\title{
Is menstruation obsolete?
}

\author{
PERSONAL VIEW Paula S Derry
}

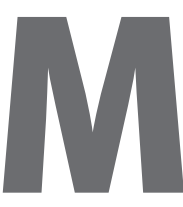

enstrual suppression has been recommended for medical conditions such as endometriosis, but it is also being proposed as a lifestyle choice for women who dislike menstruation or find it inconvenient. Articles in the professional and popular press have asserted that menstrual suppression is a reasonable lifestyle choice. Birth control options that reduce or eliminate periods are being developed. The oral contraceptive Seasonale, for example, combines 84 days of active pills ( $0.03 \mathrm{mg}$ ethinyl oestradiol and $0.15 \mathrm{mg}$ levonorgestrel) with seven days of placebo. Since menstrual flow occurs during the pill-free interval, a hormone-free interval every three months instead of the usual 21 days reduces the number of pill induced periods from 13 to four annually. Seasonale's website www.seasonale.com states: "Fewer periods. More possibilities ... you might want to consider asking about Seasonale if you ... wish you had more time between periods, and less of them."

The long term safety of menstrual suppression cannot currently be determined with experimental data. Seasonale, for example, has been approved by the Food and Drug Administration, but long term research was not required for approval. Overall, the existing data are limited, and whether or not long term risks exist remains uncertain: this would require lengthy study, of five years or more, and information about a broad range of users. Proponents have argued that menstrual suppression is safe, even beneficial, because monthly menstruation is unnecessary,
Even if monthly cycles were unnatural, this would not prove that suppressing menstruation is better authors argue that monthly menstruation throughout most of adult life is a modern development. In industrial societies the average woman has few children and therefore may have 450 menstrual cycles during a lifetime. Women in hunter-gatherer cultures and other societies without birth control average a total of 160 periods because they are either pregnant or breast feeding much of the time and, the authors assert, exemplify what was natural in the prehistoric past when human bodies evolved and throughout most of human history. Monthly menstruation throughout adulthood is therefore at odds with what female bodies were designed to do; it is unnecessary and unnatural, and not surprisingly causes disease. To eliminate periods is a boon or at worst harmless.

But if it is more common today to have monthly menstrual cycles throughout adult life, this does not in itself mean that monthly menstruation is unnatural, much less that it is a medical problem. Human biology often permits variety and flexibility for different people in different situations. Nor is lifelong menstruation necessarily a modern invention. Women in cultures without birth control may average 160 menstrual cycles, but not every woman is the "average woman.” Today, some women in societies without birth control have few even unhealthy. A seemingly scientific argument about the biological nature of women buttresses the idea that suppression can be considered safe even in the absence of experimental evidence. However, science involves logic and evidence, and the case against menstruation involves neither.

The case against menstruation was laid out in the book Is Menstruation Obsolete?-published by Oxford University Press in 1999; its

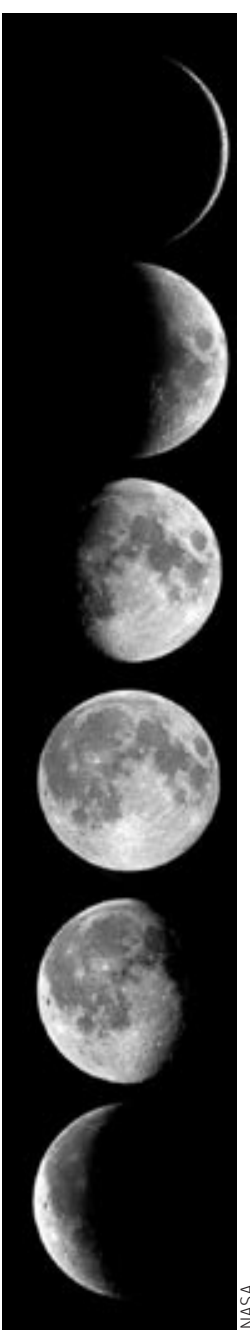

ovulating without becoming amenorrhoeic. Further, why women menstruate is unknown. Menstruation is an anomaly in nature, and we have no idea why it evolved only among humans and non-human primates. We do know that menstruation is what naturally occurs when women don't become pregnant, and that a menstruating woman is a healthy, probably fertile, woman-whereas unhealthy, malnourished, or massively stressed women are more likely to skip periods.

Even if prolonged monthly menstruation were unnatural and unhealthy, this would not prove that suppressing menstruation is better. Menstrual suppression itself is unnatural; a drug chronically overrides the physiological changes associated with the menstrual cycle, thereby creating an underlying hormonal environment that is not found in nature. Ovulation, the normal outcome of a menstrual cycle, is prevented because the hormones underlying ovulation have been suppressed. The menstrual flow is not a true period. Suppression may seem to mimic pregnancy and lactation, in the sense that there is no period, but the underlying hormonal milieu is far different.

The argument that menstruation is obsolete is illogical and unscientific. Reduced to its essentials, the argument amounts to this: too many periods can make women sick because women were meant to be constantly pregnant or breast feeding. The important questions are these: is there evidence that medications are safe and effective? What are the known benefits and risks, and what uncertainties exist with regard to future benefit and harm? Who should be using such medications? Are women provided with accurate information to make informed choices?

Paula S Derry is a health psychologist, Baltimore, MD, United States pderry@bcpl.net 


\section{Knowing what you don't know}

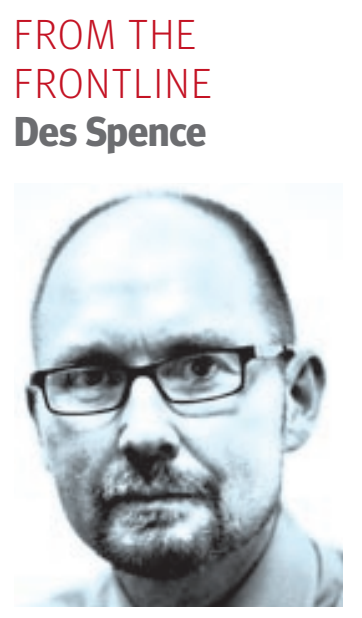

The light flashed on my buzzer. I paused for dramatic effect before saying, "Alexander Fleming." The crowd went wild. I beamed-we had won, and I had captained our team in the primary school quarter finals of the local "Top of the Form" quiz. I had the sort of memory that retained facts easily. I am like most doctors.

A decade ago I was an evidence based medicine (EBM) "fact" groupie. I loved the wild swirling data, the mind expanding NNTs (numbers needed to treat), and the geeks who thumped out PowerPoint presentations and effectively smashed up the instruments of the old medical establishment. We got drunk on the power of EBM and how it would change the world. Occasional recreational use wasn't enough-I was hooked. I pored over the classics of Cochrane and Bandolier and then sank further into Medline and PubMed. I wanted a David Sackett poster for my bedroom wall. With practice I got pretty good, and then the problems started.

I skipped discussion sections and went straight to the data tables. I started seeing confounding factors throughout papers. I lost sleep to intrusive concerns over study populations, study length, publication bias, surrogate end points, and a whole new concern, "commission- ing bias," which gives disproportionate weight to drug interventions: no research means no evidence.

But worst of all is the poor quality of the epidemiological foundation of all our facts. Simply put, the natural history of many conditions isn't known.

Take the current demand for screening for chlamydia. What is the lifetime incidence of chlamydia if the point prevalence is $10 \%$ ? Could the current observed increase merely reflect more and better testing? In the 1970s, when condoms and sexual health services were less available, surely chlamydia must have been more prevalent? What percentage of infections progress to pelvic inflammatory disease? Without this knowledge how can anyone suggest screening?

We doctors enjoy the comfort and power that facts bring, but unfortunately we apply them with an absolute certainty that they do not deserve. EBM runs the risk of becoming just as restrictive and conservative as the medical establishment that it replaced. The future challenge is to establish robust prospective epidemiological data for common medical conditions and to focus on what we don't know rather than what we think we know. Des Spence is a general practitioner, Glasgow destwo@yahoo.co.uk

\section{Grave expectations}

\section{PAST CARING \\ Wendy Moore}

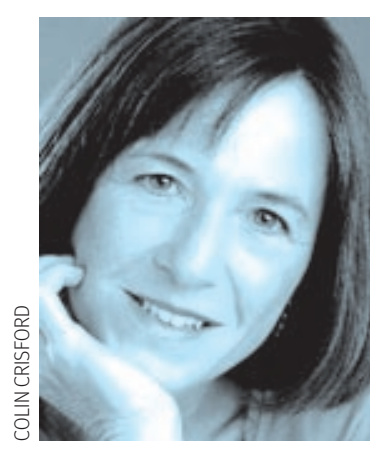

A dearth of suitable bodies has long been a cause of sleepless nights for surgeons. Today, members of the Royal College of Surgeons may toss and turn in anxiety over a predicted $30 \%$ shortfall in the 1000 bodies medical schools need annually. In 1828, surgeons giving evidence to the select committee on anatomy were just as concerned at a 200 shortfall in the 700 cadavers needed by the London schools alone. Naturally enough the source of bodies for dissection has changed-as has the reason for the sleepless nights.

Before the 1832 Anatomy Act, surgeons were accustomed to being dragged out of bed in the early hours to pay exorbitant fees to lawless gangs of body snatchers for mouldering corpses filched from paupers' graveyards. Indeed, if they did not make acceptable arrangements with the grave robbers, they might find body parts strewn at either end of their street-an easy signpost to the nightwatchmen-as anatomy teacher Joshua Brookes discovered to his cost.

But when bodies were in short supply, surgeons and students had to venture out at night to exhume suitable bodies-at the risk of being arrested, stoned, or even shot.

John Hunter almost certainly led students in night-time expeditions from his brother William's Covent Garden school to plunder nearby churchyards in the mid-1700s. But long after most anatomy teachers had found it expedient to pay the Resurrection Men to dirty their hands for them, students in Scotland, Ireland, and America still had to shift for themselves.

One distinguished professor of anatomy, giving evidence to the 1828 committee, recalled student parties in Glasgow-to graveyards, not the students' union bar-when he was often shot at by vigilante groups guarding their relatives' graves. At least, if injured, there was always a surgeon on hand.

Later, discovered with a stolen skull while teaching in Edinburgh, he had been paraded through the town, pelted with stones, and tried "like a common criminal."

In New York, surgeons had to seek refuge in the city jail when furious locals discovered their body-raising activities in 1788. And in Dublin medical students joined the university's art students for nightly expeditions to lift bodies, even in the early 19th century.

If surgeons today are relieved that their nightly exploits are more mundane, they may still look back wistfully at the diminution of their persuasive powers in the committee rooms of Westminster since 1828. Sir Astley Cooper, then president of the Royal College of Surgeons, left MPs in no doubt of his useful connections when he informed them chillingly that, "there is no person, let his station in life be what it may, whom, if I were disposed to dissect, I could not obtain." It certainly beat threatening to vote for the other side.

Wendy Moore is a freelance writer and author, London wendymoore@ntlworld.com 


\section{Green tea and monkey business}

\begin{abstract}
The name Le Fanu is not unknown to medicine in this country. There is, for example, the medical correspondent of one of our major newspapers, which it would be wrong to advertise, and W R LeFanu, who was the librarian of the Royal College of Surgeons between 1929 and 1968. A man of immense erudition, which puts one's own ignorance to shame, he oversaw the removal of the library during the second world war to
\end{abstract} Shropshire, saving it from the destruction that the college itself suffered during the blitz. A bibliographer of distinction, especially in the field of Jennerian studies, he published a bibliography of Nehemiah Grew at the age of 86, in 1990 .

Sheridan Le Fanu, the Irish writer of ghost stories, was an ancestor of his. Doctors featured very often in Le Fanu's stories; one book, In a Glass Darkly, published in 1872, is a series of the cases of one Dr Hesselius, a German specialist in "metaphysical medicine."

In the first and most famous of these stories, Green Tea, Dr Hesselius is consulted by the Reverend Mr Jennings, a clergyman in easy circumstances who, alas, is haunted. Already interested in the supernatural-books about which he stays up all night studying while drinking green tea-he one day sees two red eyes staring at him on an omnibus, which he then makes out to belong to a spectral monkey through which his umbrella can pass without meeting any resistance. The monkey stays with him for the rest of his days and grows ever more intrusive, jumping on to the Bible when he tries to read from it in church, then uttering terrible blasphemies whenever the Reverend Jennings tries to pray, and finally issuing him with commands, including that to commit suicide. Eventually, he does kill himself, by cutting his throat.

Dr Hesselius's diagnosis of the Rev- erend Jennings's distemper is cautious. It is one of Le Fanu's themes that we can never fully or definitively interpret events, and Dr Hesselius is of like opinion. In this case, he goes in for what one might call agnostic multifactorialism. First was "the habitual use of such agents as green tea," which disturb the equilibrium of the cerebral fluids. Interestingly, a National Institute of Health website informs us that when more than 8 to 10 cups of green tea per day are drunk, "symptoms of anxiety, delirium, agitation and psychosis may occur." Nor is stopping the tea necessarily instantly beneficial in those with "affective disorder or schizoaffective disorder," in whom cafffeine withdrawal can cause "confusion, disorientation, excitement, restlessness, violent behaviour, or mania."

In Dr Hesselius's opinion, one of the effects of the tea is to influence the brain so that "disembodied spirits may operate in communication more effectually." He thus makes it unclear as to whether he believes the black monkey with red eyes is a hallucination pure and simple, or an actually existing entity.

But Dr Hesselius doesn't blame the tea alone. "[Jennings'] case was in the distinctive manner a complication, and the complaint under which he really succumbed, was hereditary suicidal mania." So he was predisposed to kill himself, green tea and black monkey, or no green tea and black monkey.

As to therapy, Dr Hesselius says that iced eau de cologne applied to the forehead would have worked if applied long enough. What rubbish! Everyone knows that what the Reverend Jennings needed was an SSRI (selective serotonin reuptake inhibitor), because serotonin is the key to all human happiness and misery, and indeed to all behaviour.

Theodore Dalrymple is a writer and retired doctor
MEDICAL CLASSICS The Final Diagnosis By Arthur Hailey

\section{First published 1959}

"As is your pathology, so is your practice," said Sir William Osler, the philosopher-physician over 100 years ago. While today some may not entirely agree with the sweeping generalisation of the statement, it remains a fact that pathology forms the bedrock of medicine. Arthur Hailey, too, recognised this fact when he wrote The Final Diagnosis in 1959. While most novels and movies dealing with medicine revolve around clinicians, particularly surgeons, Hailey decided to make the department of pathology and the pathologist the core of the action. Surgeons and other physicians in the hospital are, of course, important players; they have to be, because, after all, pathology makes its existence felt after the surgeon has made the first move.

When I first read the book just over a quarter of a century ago, I fell in love with the idea of working in a big hospital. Small wonder then that I chose this book as a must read for all doctors (BMJ 2005;331:1482). In retrospect, having read it again recently, the plot is nothing spectacular: it's just another month in the life of a busy general hospital, the Three Counties in Pennsylvania. But, as anyone who's worked in a big hospital knows, every month is interesting and carries its own, different challenges. There is, just as in other Arthur Hailey novels, a multitude of characters, each with their own subplots. The story weaves around the working relationships between the many physicians and others who run the hospital.

Joe Pearson is the chief of pathology; once an excellent pathologist, he is now out of touch with the latest methods in laboratory medicine. Change is under way at the Three Counties Hospital, and Pearson faces the possibility of losing his job. That, however, could lead to loss of a substantial donation

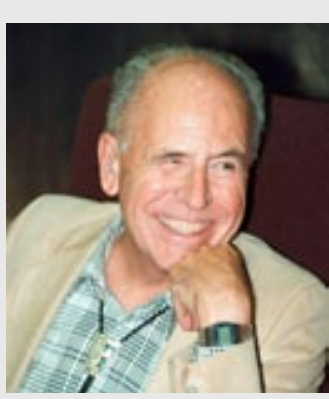

Arthur Hailey: meticulous to the hospital, from a rich benefactor, who is a friend of Pearson's. Just as the surgeonadministrator Kent O’Donnell weighs the pros and cons of his decisions, Hailey balances O'Donnell's professional life with his love life. Tragedy surfaces in the book, as it does in real life

in hospitals, when doctors make errors, or when terrifying diseases strike young, likeable people.

The story is readable nearly 50 years after it was first published. Some of the scenes are melodramatic, at least from a physician's viewpoint. But the issues that Hailey deals with are as relevant now as in 1959. Equally striking - and a reflection of the meticulous research that the author was famous for-is the fact that there are no bloomers in Hailey's descriptions of various medical procedures. Perhaps for the first time, non-medical readers were introduced to the concept of frozen sections, clinico-pathological conferences, and doubt and uncertainty in medicine. Sanjay A Pai, consultant pathologist, Manipal Hospital, Bangalore, India sanjayapai@gmail.com 


\section{Lies with everything}

Janice Hopkins Tanne is horrified by a film about America's burger industry

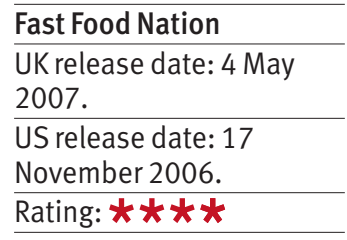

\section{The film highlights fast food companies' need for illegal and poorly paid immigrant labour}

You may never eat a hamburger again after seeing Fast Food Nation. You may even become a vegetarian.

This film, based on award winning journalist Eric Schlosser's eponymous bestseller (BMJ2002;324:1461), is far more than an exposé of the fast food chains that have spread across the world, oozing like ketchup from their American birthplace and providing standardised hamburgers and fries (chips) to millions.

It describes the fast food industry's influence on what we eat, on illegal immigration to the United States, on agriculture, on globalisation, on environmental impact, on dead-end and sometimes dangerous jobs, on real estate interests, and on how middle America thinks about work.

The film's subtitle is "You want lies with that?"-a pun on McDonald's "You want fries with that"-whereas Schlosser's book was subtitled "The Dark Side of the All-American Meal." His opening chapter described a man who most days delivered pizza to the well guarded North American Aerospace Command inside Cheyenne Mountain in Colorado. Other chapters described the growth of the fast food industry.

The film is different and translates the complex history of the fast food industry into easily grasped fictional stories of the people involved. It begins with a group of young Mexicans illegally entering the United States with a dangerous journey through the Arizona desert. Some will die. Those who survive are transported to several cities for "off the books" work that nevertheless pays immensely more than they could earn at home. Some wind up in the imagined small city of Cody, Colorado.

In parallel, we see a marketing executive (played by Greg Kinnear), a nice family guy, who has been successful at his company by inventing and promot-

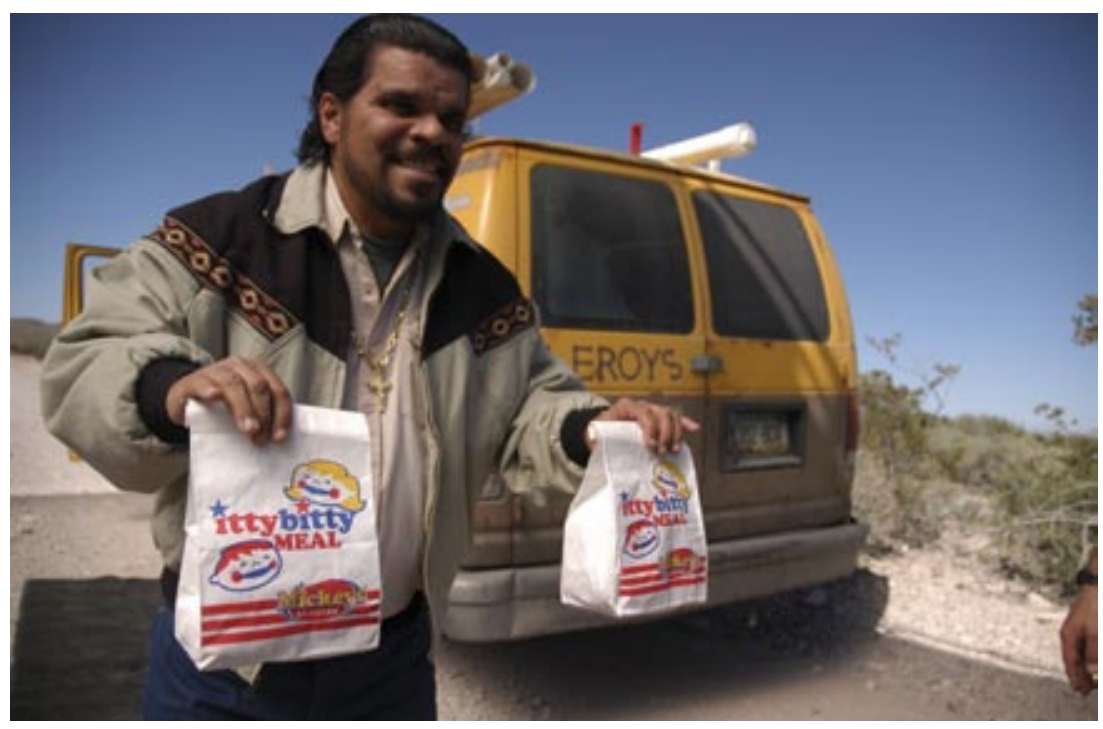

ing "The Big One" hamburger for his fastfood chain, called Mickey's, and who is involved in the chemical processes used to improve the burger's smell and taste. However, like many middle Americans, he is worried about his job.

He hears from his boss that a watchdog group has found high levels of faecal coliform bacteria-E coli-in the frozen hamburger patties that Mickey's ships from Colorado to its many fast food outlets, where the patties are quickly cooked and packed into "The Big One" hamburgers. "There's shit in the meat," barks his boss.

The marketing executive is sent to investigate the contamination problem at Cody, which supplies Mickey's meat. Thousands of cattle fill mile after mile of huge feedlots, where their manure and urine contaminate the land and water all around. Then they are sent to a plant, where they are slaughtered, butchered, turned into round, pink hamburger patties, frozen, and shipped out nationwide. The executive is taken on a tour through an apparently spotless, sanitary plant. "You didn't see the kill floor," people tell him.

A man who sells cattle from ranchers to the meatpacking conglomerate-brilliantly played by Bruce Willis-discounts the problem of faecal contamination: "Meat is supposed to be cooked. Just cook it," he says.

A rancher explains how real estate interests are trying to take over the land where he has raised cattle like his forefathers. They are building whole suburban communities on what was once ranchland.

The illegal Mexican immigrants find jobs at Cody's meat processing plant. The work is gruelling and dangerous and the hours are long. Sexual exploitation of women is common.

Sometimes workers take drugs to take the edge off. Nevertheless, they are glad to have the jobs, which pay them more in an hour than they would make in a day in Mexico and enable them to send money home to their families. They are drawn into lower middle class life: buying a used car, taking a girlfriend out for a meal at a fast food restaurant.

Some scenes are scary, showing workers using sharp knives and electric blades with no apparent safety devices. One scene is devastating.

Beyond the obvious fast food story, the film cleverly entwines many aspects of US life: its corporate culture, which the film says is corrupt; companies' need for illegal and poorly paid immigrant labour; workers who are only too happy to stay in terrible jobs for higher pay than they could get at home; and workers who are on drugs because their work is so demeaning, which puts them at risk of injury on the job.

Janice Hopkins Tanne is a medical journalist, New York TanneJH@aol.com 